\title{
To study the outcome of vaginal reconstructive surgery for isolated rectocele
}

\section{Bhavana Gupta}

Professor and HOD, Dept. of Obstetrics and Gynaecology, Integral Institute of Medical Science and Research, Lucknow, Uttar Pradesh, India

\author{
*Corresponding Author: Bhavana Gupta \\ Email: bhavana_yajat@yahoo.com
}

Received: $18^{\text {th }}$ September, 2018

Accepted: $27^{\text {th }}$ February, 2019

\begin{abstract}
Aim: To study the symptomatic relief of local and bowel symptoms after vaginal reconstructive surgery for isolated rectocele.

Introduction: Isolated posterior compartment defect as isolated rectocele is on the raise due to multi parity and chronic constipation, sedentary and faulty lifestyle. The term rectocele means herniation of rectum into vaginal canal. The posterior wall defect presented with difficult defecation, constipation, incomplete evacuation, pressure in recto vaginal area, manual vaginal replacement during evacuation. The cases with isolated rectocele were evaluated and relief of local and bowel functions before and after the pelvic repair were assessed.

Materials and Methods: A prospective study was done between August 2016-August 2018, for the period of 2 years at IIMSR, Dasauli, dept. of OBG, Lucknow wherein cases with isolated rectocele were identified and pelvic repair of the rectocele was done by repair of pararectal fascia without mesh along with pelvic floor repair wherein the medial fibres of levator ani was approximated. Out of 426 cases presenting to the gynaecology OPD with mass per vagina, local pressure symptoms, after detailed history and examination, 25 cases of isolated rectocele were included in the study.

Result: A total of 25 cases out of $426(5.86 \%$ ) were with isolated rectocele. 25 cases underwent pelvic repair of the rectocele by repair of pararectal fascia without mesh,excision of redundant vagina along with pelvic floor repair with approximation of medial fibres of levator ani muscles. There was significant association between isolated rectocele, chronic constipation and multi parity. The statistical analysis was done using chi square and pvalue.
\end{abstract}

Keywords: Isolated rectocele, Chronic constipation, Pelvic repair.

\section{Aim}

To study the symptomatic relief of local and bowel symptoms after vaginal reconstructive surgery for isolated rectocele.

\section{Materials and Methods}

A prospective study was done between August 2016-August 2018, for the period of 2 years at Integral Institute of Medical Sciences and Research, Dasauli, kursi Road, department of OBG, Lucknow, where in cases with isolated rectocele were identified and pelvic repair of the rectocele was done by repair of pararectal fascia without mesh along with pelvic floor repair wherein the medial fibres of levator ani was approximated. Out of 426 cases presenting to the gynaecology OPD with mass per vagina and local pressure symptoms, after detailed history and examination, 25 cases of isolated rectocele were included in the study.

Out of 426 cases screened, the patients with uterine prolapse, cystocele, uterine tumours, dysfunctional uterine bleeding, rectal prolapse, haemorrhoids, post hysterectomy vault prolapse, irritable bowel syndrome were excluded. Only patients with isolated rectocele, 25 cases were identified in the study. The associated factors chronic constipation, multiparity were analysed. The main outcome in the form of pressure symptom relief and functional bowel outcome were analyzed.

\section{Result}

A total of 25 cases out of $426(5.9 \%)$ were with isolated rectocele. 25 cases underwent pelvic repair of the rectocele by repair of pararectal fascia without mesh, excision of redundant vagina along with pelvic floor repair with approximation of medial fibres of levator ani muscles. Out of 25 cases 23 cases $(92 \%)$ had significant improvement in the pressure and bowel symptoms. 2 cases had relief from local pressure symptoms, but had no relief from chronic constipation. 23 of 25 cases were associated with chronic constipation. 25 of 25 cases had multiparity with vaginal delivery at home by untrained personnel. There was significant association between isolated rectocele and chronic constipation. The significance of association between categorical variables - isolated rectocele, multiparity and chronic constipation was calculated by chi square and estimation of $\mathrm{p}$-value.

Out of 426 cases screened, in which 25 cases found with isolated rectocele. Prevalence of isolated rectocele was observed $5.9 \%$.

Table 1: shows the descriptive statistics

\begin{tabular}{|l|l|c|}
\hline & Constipation & Multi parity \\
\hline Mean & .92 & 1.00 \\
\hline Std. Deviation & .277 & .000 \\
\hline Variance & .077 & .000 \\
\hline Skewness & -3.298 & \\
\hline Std. Error of Skewness & .464 & .464 \\
\hline Kurtosis & 9.641 & \\
\hline Std. Error of Kurtosis & .902 & .902 \\
\hline
\end{tabular}


Table 2: Shows the frequency distribution of cases with respect to Constipation

\begin{tabular}{|l|c|c|c|}
\hline \multirow{2}{*}{} & \multicolumn{3}{|c|}{ Constipation } \\
\cline { 2 - 4 } & Number of Cases & Percentage & Cumulative Percent \\
\hline No Improvement & 2 & $8 \%$ & 8 \\
\hline Improvement & 23 & $92 \%$ & 100 \\
\hline
\end{tabular}

Table 3: Shows the frequency distribution of cases with respect to Multi parity

\begin{tabular}{|c|c|c|}
\hline \multirow{2}{*}{} & \multicolumn{2}{|c|}{ Multi parity } \\
\cline { 2 - 3 } & Number of Cases & Percentage \\
\hline Positive & 25 & 100 \\
\hline
\end{tabular}

Association between variables i.e., Chi square value is 17.64 The two-tailed $P$ value is less than 0.0001

By conventional criteria, this difference is considered to be extremely statistically significant.

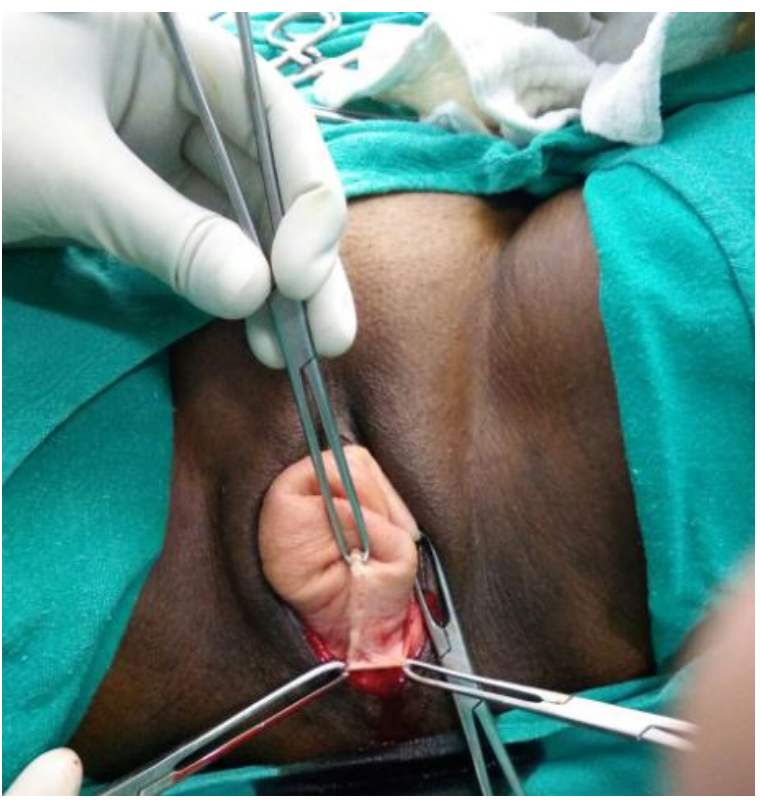

Fig. 1:

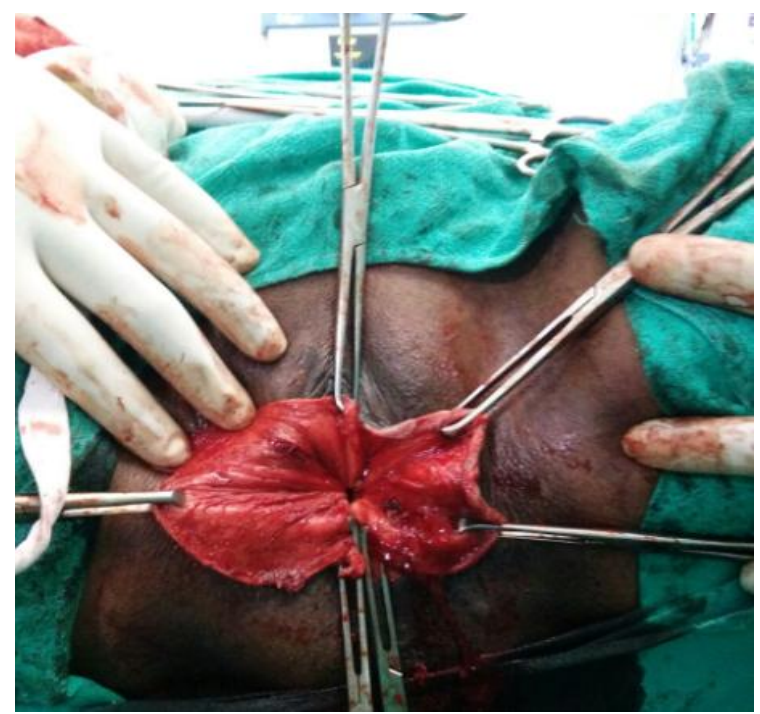

Fig. 2:

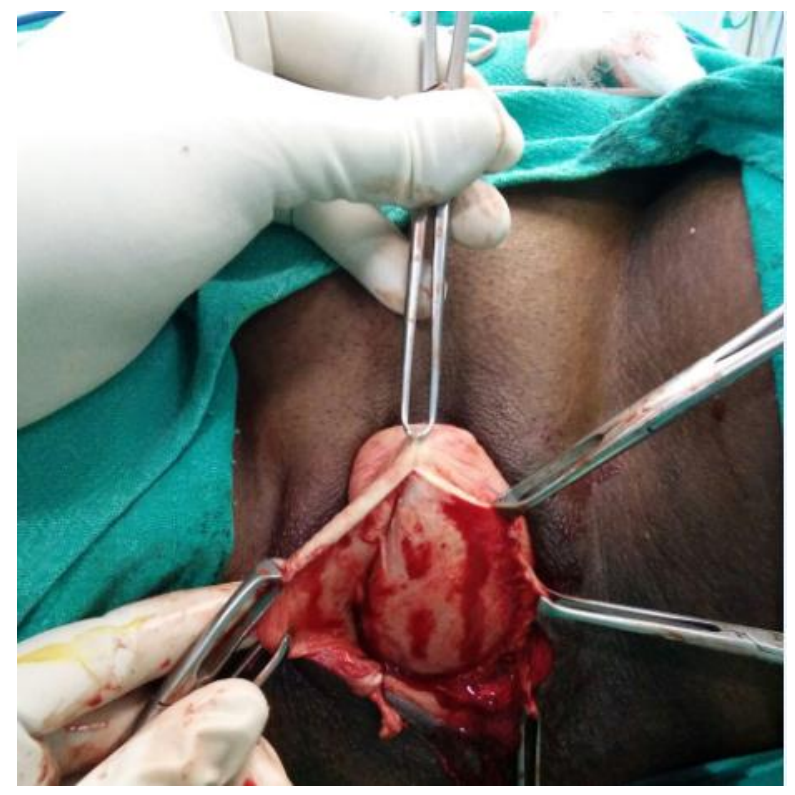

Fig. 3:

\section{Discussion}

The herniation of the front wall of rectum into the posterior wall of the vagina is called the rectocele. The tissue between the rectum and the vagina is known as rectovaginal septum and this structure if thin and weak results in rectocele.

A rectocele may be an isolated finding or occur as part of generalized weakening of pelvic floor muscles. The weakening of pelvic floor can occur due to advanced age, multiple vaginal deliveries and birthing trauma during vaginal delivery. Apart from this, chronic constipation and excessive straining with bowel movements can cause rectocele.

Rectocele may cause rectal and vaginal symptoms. The rectal symptoms are difficulty in evacuation during bowel movements and need to press against back wall of the vagina and/or space between rectum and vagina (perineal body) in order to have bowel movement. The vaginal symptoms include the sensation of bulge or fullness in the vagina, discomfort in sexual intercourse and vaginal bleeding. Symptomatic rectocele can lead to excessive straining with bowel movements, urge to excessive straining with bowel movement, urge to have multiple bowel movements throughout the day with rectal discomfort. Significant stool strapping may occur in some patients.

The incidence of rectocele is $20-80 \%$ in general population and is thought to be increasing. Most recently, rectocele and enterocele were noted to occur in approximately $40 \%$ of asymptomatic parous women. Rectocele may have broader incidence than previously thought and may not be a result of parity. 
The most common causes of rectocele are obstetric events. Traumatic obstetric events, constipation results in evertion of introitus resulting in efficient bowel movement need for valsalva manouvre.Rectocele may result from secondarily from pathologic stretching of the pudental nerves during descent of the fetal head, causing atrophy and denervation of pelvic floor muscles. Electromyography studies shows $80 \%$ occurrence of denervation of perineal nerves after vaginal delivery. Denervation recovers after the postpartum period. However, it has been shown injury may

be cumulative with increasing parity. Defecation disorders may cause a subgroup of rectocele due to weakening of rectovaginal septum. Paradoxical sphincter reaction (Anismus) may lead to individual unconsciously contracting the voluntary striated muscles to defecate resulting in stool in rectum and worsening of rectocele.

The pelvic floor disorders had profound effect on women's life and affect enormous percentage of adult female population. The life time risk of surgery for pelvic floor disorder is $11.1 \% .^{1,2}$ The co-morbidity of these cases needs evaluation of urinary, fecal, pelvic floor function. $76 \%$ of women with pelvic organ prolapsed have defects of posterior vaginal wall. ${ }^{2-4}$ The epidemiological, neurological and postpartum anal sphincters ultrasound studies would suggest that trauma during vaginal delivery may result in pelvic floor disorders. ${ }^{5-8}$

The studies have shown, chronic straining with constipation may result in peripheral neuropathy and stretching of connective tissue between anterior rectum and posterior vaginal wall. ${ }^{9-13}$ The posterior wall defect presented with difficult defecation, constipation, incomplete evacuation, pressure in rectovaginal area, manual vaginal replacement during evacuation. ${ }^{14-17}$

The pelvic organ prolapsed quantification system was followed for clinical examination. The patient was examined in lithotomy position or semirecumbent position using a Sims speculum/bivalve speculum with maximum valsalva effort. $^{18,19}$

Studies have shown there is considerable improvement in anatomical and functional outcome following surgery. ${ }^{19-23}$ The treatment of asymptomatic posterior wall defect is controversial. Conservative management using diet and behavioral modification should also be simultaneously addressed. The overall success of the surgery depends on the symptoms, length of time symptoms have been present and approach of surgery. Some studies report significant improvement in $75-90 \%$ of patients. A surgeons familiarity with technique and experience in repairing rectocele also influence the result. The traditional rectocele approach was described by Nichols and Wheelers. Here by a inverted $\mathrm{T}$ incision, a triangular wedge of vagina wall is excised. The rectovaginal fascia is approximated with interrupted sutures. Medial fibres of levator ani muscles are approximated and perineal body is repaired. The posterior vaginal mucosa is trimmed and approximated with continuous absorbable sutures. Other methods are transrectal repair, transabdominal repair, mesh/graft augmentation. ${ }^{24-26}$
Many surgeons ascertained that the main support of the uterus was the vagina, which was supported by insertion of levator ani muscles into the perineum. This concept was the basis for incorporation of placation of levator ani muscle placation into posterior colpoperineorraphy. Some of the complications of rectocele repair mentioned in the literature were bleeding, constipation, difficulty in passing stools, dyspareunia, pelvic pressure, proctotomy, rectovaginal fistula. Three different surgical techniques are used to repair symptomatic rectocele: levator placation, site-specific repair, and transanal and trans abdominal repair. They all can be done with or without mesh/graft augmentation. Gynaecologic surgeons have traditionally advocated transvaginal repair involving levatorplasty.

\section{Conclusion}

In rural setup due to limited infrastructure and economic constraints if isolated rectocele/posterior compartment defect is corrected meticulously with expertise, by repair of pararectal fascia without mesh with excision of redundant vagina along with pelvic floor repair with approximation of medial fibres of levator ani muscles offered considerable relief from pressure and bowel symptoms. More than $11 \%$ of women who reach age of 80 undergo surgery for urinary incontinence or genital prolapse. As the society ages, the population suffering from rectocele or defecation disorders will increase. The clinicians will need to be well versed in proper evaluation and the operative techniques to manage the defects. More research is needed to be done to understand the correlation between anatomic defect and functional derangement that occurs secondary to posterior wall prolapse.

\section{Limitation}

Due to economic constraints and rural setup, mesh was not used. Further comparative study between mesh and non mesh outcome can be done. As the study was for 2 years, further long term outcome needs to be studied.

\section{Conflict of Interest: None.}

\section{Reference}

1. Kleeman SD, Westermann.C, KarramMM. Rectocele and anatomy of posterior vaginal wall: revisited. Am J Obstet Gynecol 2005;193(6);2050-5. http://doi.org/10.1016/j.acog.2005.07.096.

2. Lene DuchMadsen, Emil Nursler, Ulrik Scholar kas Modell et al. Native tissue repair of isolated primary rectocele compared with non absorbable mesh. Patient reported outcome. Int Urogynaecology J 2017;28(1):49-50.

3. Emily S. Lukaez, MD and Karl M. Luber, MD. Rectocele repair: when and how? Curr Urol Rep 2002;3:418-22.

4. Davila GW, Ghoniem GM, Kapoor DS, Contreras-Ortiz O. Pelvic floor dysfunction management practice patterns: a survey of members of the International Urogynecological Association. Int Urogynecol J 2002;13:319-25.

5. Kapoor DS, Davila GW, Wexner SD, Ghoniem GM. Posterior compartment disorders: survey of colorectal surgeons practice patterns and review of the literature. Int Urogynecol $J$ 2001;12:S53. 
6. Mizrahi N, Kapoor D, Baig MK. A gynecologic perspective of posterior compartment defects. Colorectal Dis 2002;4:68.

7. Delancey JOL, Hurd WW. Size of the urogenital hiatus in the levator ani muscles in normal women and women with pelvic organ prolapse. Obstet Gynecol 1998;91:364-8.

8. Milley PS, Nichols DH.A correlative investigation of the human rec-tovaginal septum. Anat Rec 1969;163:443-52.

9. Richardson AC. The rectovaginal septum revisited: its relationship to rectocele and its importance in rectocele repair. Clin Obstet Gynecol 1993;36:976-83.

10. Uhlenhuth E, Wolfe WM, Smith EM, Middleton EB. The rectogenital septum. Surg Gynecol Obstet 1948;86:148-63.

11. Birch C, Fynes MM. The role of synthetic and biological prostheses in reconstructive pelvic floor surgery. Curr Opin Obstet Gynecol 2001;14:527-35.

12. Iglesia CB, Fenner DE, Brubaker L. The use of mesh in gynecologic surgery. Int Urogynecol J 1997;8:105-15.

13. Sand PK, Koduri S, Lobel RW. Prospective randomized trial of polyglactin 910 mesh to prevent recurrences of cystoceles and rec-toceles. Am J Obstet Gynecol 2001;184:1357-64.

14. Parker MC, Phillips RKS. Repair of rectocoele using Marlex mesh. Ann R Coll Surg Engl 1993;75:193-4.

15. Watson SJ, Loder PB, Halligan S. Transperineal repair of symptomatic rectocele with Marlex mesh: a clinical, physiological and radiological assessment of treatment. $J \mathrm{Am}$ Coll Surg 1996;183:257-61.

16. Nichols DH. Posterior colporrhaphy and perineorrhaphy: separate and distinct operations. Am J Obstet Gynecol 1991;164:714-721.

17. Francis WJ, Jeffcoate TN. Dyspareunia following vaginal operations. J Obt Soc Am 1961;68:1-10.

18. Mellgren A, Anzen B, Nilsson BY. Results of rectocele repair. A prospective study. Dis Colon Rectum 1995;38:7-13.
19. Lopez A, Anzen B, Bremmer S. Durability of success after rectocele repair. Int Urogynecol J Pelvic Floor Dysfunct 2001;12:97-103.

20. 20.Kahn MA, Stanton SL. Posterior colporrhaphy: its effects on bowel and sexual function. Br J Obstet Gynaecol 1997;104:82-6.

21. Paraiso MF, Weber AM, Walters MD, Ballard LA, Piedmonte MR, Skibinshi C. Anatomic and functional outcome after posterior col-porrhaphy. J Pelvic Surg 2001;7:335-9.

22. Cundiff GW, Weidner AC, Visco AG, Addison WA, Bump RC. An anatomic and functional assessment of the discrete defect rectocele repair. Am J Obstet Gynecol 1998;179:145157.

23. Glavind K, Madsen H. A prospective study of the discrete fascial defect rectocele repair. Acta Obstet Gynecol Scand 2000;79:145-7.

24. Kenton K, Shott S, Brubaker L. Outcome after rectovaginal reattach-ment for rectocele repair. Am J Obstet Gynecol 1999;181:1360-63.

25. Porter WE, Steele A, Walsh P, Kohli N, Karram MM. The anatomic and functional outcomes of defect-specific rectocele repairs. Am J Obstet Gynecol 1999;181:1353-1358.

26. Nichols DH, Randall CL: Posterior colporrhaphy and perineorraphy.In Nicholas DH, Randall CL (eds): Vaginal surgery, $4^{\text {th }}$ edition,pp257-289,Baltimore,WILLIAMS \&Wilkins.1996.

How to cite this article: Gupta B, To study the outcome of vaginal reconstructive surgery for isolated rectocele. Indian J Obstet Gynecol Res 2019;6(2):133-136. 